\title{
Preferential reduction of dicentrics in reciprocal exchanges due to the combination of the size of broken chromosome segments by radiation
}

Received: 30 June 2003/ Accepted: 8 August 2003/Published online: 23 September 2003

(C) The Japan Society of Human Genetics and Springer-Verlag 2003

\begin{abstract}
Induction rates of the dicentrics and translocations involving chromosomes 2 and 4 in peripheral lymphocytes irradiated with X-rays at a dose of 3 Gy were examined using a conventional Giemsa staining method and a chromosome painting method. In total, 228 reciprocal exchanges detected in 982 metaphases were classified into three groups according to the break points of the original chromosomes. The incidence of both acentric fragments being larger than half of the original chromosome (combination 1) was only seven $(3 \%)$ and did not contribute significantly to induction rates. When the broken acentric fragments of two affected chromosomes were smaller than half of the original chromosomes (combination 2), which was found in $175(77 \%)$ rearrangements, the induction rates of dicentrics and translocations were about the same (86:89). But if the sizes of the broken segments were unequal in both chromosomes (combination 3: one with a larger acentric part and the other with a smaller acentric part), the yield of dicentrics was significantly lower than that of translocations (16:30). It was suggested that there was a special mechanism causing preferential reduction of dicentrics in reciprocal exchanges originated from the heteromorphic size of broken chromosomes in the last combination.
\end{abstract}

Keywords Dicentrics · Translocations - Induction rate $\cdot$ Chromosome rearrangements $\cdot$ Radiation . Human lymphocytes

W. Zhang

National Institute for Radiological Protection and Nuclear Safety, Chinese Center for Disease Control and Prevention, 100088 Beijing, China

W. Zhang $\cdot$ I. Hayata $(\bowtie)$

Radiation Hazards Research Group,

Research Center for Radiation Safety,

National Institute of Radiological Sciences,

Chiba 263-8555, Japan

E-mail: hayata@nirs.go.jp

Tel.: +81-43-2063080

Fax: + 81-43-2519231

\section{Introduction}

Dicentrics and translocations in lymphocytes are the most useful indicators of radiation dose assessment. When breakages occur at one point in each of two chromosomes, an asymmetrical rearrangement leads to a dicentric and a fragment and a symmetrical rearrangement results in a translocation. If the rejoining occurs randomly, dicentrics and translocations will be produced in an equal ratio. However, the actual observed rates of radiation-induced translocations are higher in general than that of dicentrics (1.63-9 fold, Lucas et al. 1989; 1-12.33 fold, Cremer el al. 1990; 1.5-2 fold, Natarajan et al. 1992; 1-3 fold, Tucker et al. 1993; 1.67-4 fold, Boei et al. 1996; greater than 1, VirsikPeuckert et al. 1997; 1.4 fold, Finnon et al. 1995; 1.33.75 fold, Luomahaara et al. 1999; 1.55-2.79 fold, Schmid et al. 1992; 1.11-3.67 fold, Bauchinger et al. 1993; an observed high number in translocations at most dose points, Nakano et al. 1993; 1.2 fold, Knehr et al. 1999). A study previously reported from our laboratory (Kanda et al. 1996), in which cells in the second division and misclassification of aberrations were carefully excluded, also showed a slightly higher number of translocations, although the difference was not statistically significant. Natarajan et al. 1994 suggested the difference in the mechanisms of the misrepair process as a possible explanation for the high incidence of translocations. The mechanism of what contributes to the formation of translocations and dicentrics resulting from pairwise interactions of two radiation-induced broken chromosomes is still unknown.

In order to understand why translocations were induced more frequently than dicentrics, we analyzed the lengths of the pieces of chromosomes involved in the rearrangements. We found that the yield of dicentrics was significantly lower than that of translocations when original chromosomes were heteromorphic in the size of broken segments; one chromosome consists of a small centric piece and a large acentric fragment, and the other 
consists of a large centric piece and a small acentric fragment.

\section{Materials and methods}

Irradiation and chromosome preparation

Peripheral blood was drawn into heparinized vacutainers from a healthy 33-year-old man. It was immediately irradiated with $200 \mathrm{kV}$ X-rays at a dose of $3.0 \mathrm{~Gy}$ and kept at $37^{\circ} \mathrm{C}$ for $3 \mathrm{~h}$. Then the lymphocytes were separated from the blood and cultured in RPMI1640 containing $20 \%$ fetal calf serum for $48 \mathrm{~h}$ in the presence of Kanamycin $(60 \mu \mathrm{g} / \mathrm{ml})$, PHA $(0.2 \%)$ and Colcemid $(0.05 \mu \mathrm{g} / \mathrm{ml})$. The cultured cells were treated with a $\mathrm{KCl}$ hypotonic solution $(0.075 \mathrm{M})$ at $37^{\circ} \mathrm{C}$ for $20 \mathrm{~min}$ and fixed with acetic alcohol $(1: 3)$. Air-dried slides were made under warm and humid conditions (Hayata et al. 1992).

Image acquisition of chromosome rearrangements

The chromosome slides were stained with Giemsa's solution. Wellspread metaphases were photographed at high magnification $(\times 60$ objective) with a digital camera system (Olympus). The positions of metaphases on the slides were recorded using an automated stage system (Nikon). The Giemsa staining was washed out with acetic alcohol. The slides were processed following the method reported by Kanda et al. 1996. Chromosome painting by FISH with composite whole chromosome-specific DNA libraries for human chromosomes 2 and 4 (Cambio, Cambridge, UK) was performed according to the method described by Yamada et al. 1996 with a slight modification. Those chromosomes were chosen for painting because they were large and not metacentric. The recorded positions of metaphases in the Giemsa stained slides were relocated and the painted images of the same metaphases were photographed again by the digital camera system when there was a rearrangement in chromosomes 2 and 4.

Comparison of the sizes of rearranged segments

The size of the rearranged piece compared with the total length of the original chromosome was decided by comparing both images (Giemsa-stained and FISH-painted) using the Microsoft Windows 'Painter' program. If a piece was larger than half the original chromosome, it was called large; if it was smaller than half, it was called small. When both pieces were the same size, they were called medium. Rearrangement involving the medium pieces was not included in the present analysis. Therefore, all translocations and dicentrics in this study originated from three combinations of broken chromosome pairs (Fig. 1). Combination 1: Both chromosomes consisted of a small centric piece and a large acentric piece (SC+LA and SC+LA). Combination 2: One chromosome consisted of a small centric piece and a large acentric piece, and the other of a large centric piece and a small acentric piece $(\mathrm{SC}+\mathrm{LA}$ and $\mathrm{LC}+\mathrm{SA}$ ). Combination 3: Both chromosomes consisted of a large centric piece and a small acentric piece ( $\mathrm{LC}+\mathrm{SA}$ and $\mathrm{LC}+\mathrm{SA}$ ). To assess the relationship between break-points and the incidence of aberrations, only reciprocal translocations $[\mathrm{t}(\mathrm{Ba})$, $\mathrm{t}(\mathrm{Ab})]$ and dicentrics with a fragment [dic(BA) ace(ba)] (Tucker et al. 1995) occurring as a simple rearrangement were used.

\section{Statistical analysis}

Assuming that dicentrics and translocations in each case are produced with equal frequency and that breaks and rejoins occur randomly, statistical tests based on the normal approximation to the binominal distribution were performed.

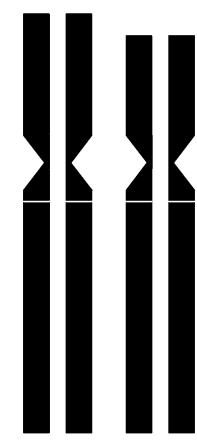

$S C+L A \& S C+L A$
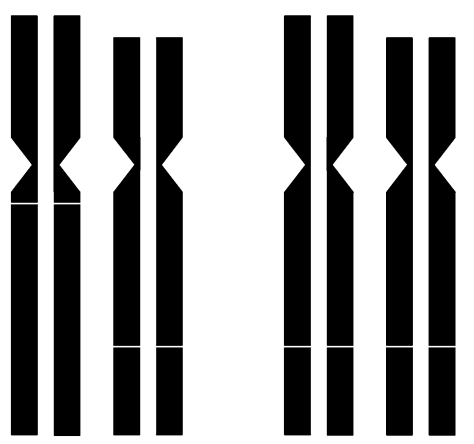

$S C+L A \& L C+S A \quad L C+S A \& L C+S A$

\section{Combination $1 \quad$ Combination $2 \quad$ Combination 3}

Fig. 1 Three combinations of original chromosomes according to the lesions induced by radiation. $L C$ large centric, $L A$ large acentric, $S C$ small centric, $S A$ small acentric

\section{Results and discussion}

One hundred six dicentrics and 125 translocations were found in 982 metaphases. However, 105 dicentrics and 123 translocations were subjected to the following analysis, as the rest involved the central chromosomal region in the rearrangements (see Materials and methods). The numbers of observed dicentrics and translocations involving chromosomes 2 and 4 are shown in Table 1, where expected numbers for respective rearrangements are also indicated.

The expected values were calculated as follows: According to Mayall et al. 1984, the relative size of chromosomes 2 and 4 are 4.19 and 3.31, and centromere indexes (10xlong arm length/total length) of chromosomes 2 and 4 are 6.13 and 7.28, respectively. When we assumed that radiation induced breaks and joining randomly along these chromosomes, the ratio of chromosomal rearrangements involving each chromosome 2 and 4 was $559: 441[4.19 /(4.19+3.31)$ versus $3.31 /$ $(4.19+3.31)]$. If translocations and dicentrics are produced in the equal frequency, rearrangements involving chromosomes 2 and 4 are expected to be 63.7 and 50.3 cases in the total of 228 cases. Acentric fragments longer than half of the original chromosomes (SC+LA) are expected to be produced in $11.3 \%(0.613-0.5)$ and $22.8 \%(0.728-0.5)$ for chromosome 2 and 4 . As average centromere indexes of other chromosomes excluding either chromosome 2 or 4 are 6.72 and 6.63, respectively, acentric fragments longer than half of the original chromosomes (SC+LA) are expected to be produced in $17.2 \%$ and $16.3 \%$ of these cases. The probability of producing of $\mathrm{LC}+\mathrm{SA}$ is 1 minus the probability of producing of $\mathrm{SC}+\mathrm{LA}$. Thus, the probabilities of respective combinations $(1,2$, and 3 in Fig. 1) are obtained by the following formula: $\left(p_{n} \times p_{\text {exn }}\right),\left(p_{n} \times q_{\text {exn }}\right.$ $\left.+p_{\text {exn }} \times q_{n}\right)$ and $\left(q_{n} \times q_{e x n}\right)$, where $p_{n}$ and $p_{\text {exn }}$ are the probabilities of producing of SC + LA with the painted chromosome (chromosome 2 or 4 ) and with other 
Table 1 Incidences of dicentrics and translocations made from different original combinations in 228 rearrangements induced by radiation. Combination $1(\mathrm{SC}+\mathrm{LA}$ and $\mathrm{SC}+\mathrm{LA})$ : Both chromosomes consist of a small centric piece and a large acentric piece. Combination 2(SC $+\mathrm{LA}$ and $\mathrm{LC}+\mathrm{SA})$ : One chromosome consists of a small centric piece and a large acentric piece, and the other consists of a large centric piece and a small acentric piece. Combination 3(LC $+\mathrm{SA}$ and $\mathrm{LC}+\mathrm{SA})$ : Both chromosomes consist of a large centric piece and a small acentric piece. Theoretical values by assuming the rearrangements occur randomly are shown in parenthesis

\begin{tabular}{|c|c|c|c|c|c|c|c|}
\hline \multirow[t]{2}{*}{ Original combination } & \multicolumn{3}{|c|}{ Dicentrics involving chromosomes: } & \multicolumn{3}{|c|}{ Translocations involving chromosomes: } & \multirow[t]{2}{*}{ Total } \\
\hline & 2 & 4 & 2 and 4 & 2 & 4 & 2 and 4 & \\
\hline $1(\mathrm{SC}+\mathrm{LA}$ and $\mathrm{SC}+\mathrm{LA})$ & $1(1.2)$ & $2(1.9)$ & $3(3.1)$ & $2(1.2)$ & $2(1.9)$ & $4(3.1)$ & $7(6.2)$ \\
\hline $2(\mathrm{SC}+\mathrm{LA}$ and $\mathrm{LC}+\mathrm{SA})$ & $7(15.7)$ & $9(15.9)$ & $16^{\mathrm{a}}(31.6)$ & $12^{f}(15.7)$ & $18(15.9)$ & $30(31.6)$ & $46(63.2)$ \\
\hline $3(\mathrm{LC}+\mathrm{SA}$ and $\mathrm{LC}+\mathrm{SA})$ & $50^{\mathrm{d}}(46.8)$ & $36(32.5)$ & $86^{\mathrm{b}}(79.3)$ & $53^{\mathrm{g}}(46.8)$ & $36(32.5)$ & $89(79.3)$ & $175(158.6)$ \\
\hline Total & $58^{\mathrm{e}}(63.7)$ & $47(50.3)$ & $105^{\mathrm{c}}(114)$ & $67^{\mathrm{h}}(63.7)$ & $56(50.3)$ & $123(114)$ & $228(228)$ \\
\hline $\begin{array}{l}\mathrm{a}, \mathrm{b}, \mathrm{c}, \text { Dicentrics } / \text { dicentrics } \\
\text { its were } 0.378 \pm 0.144 \text { for } \\
0.491 \pm 0.074 \text { for }^{\mathrm{b}} \text { (not } \\
\text { significant) }\end{array}$ & $\begin{array}{l}\text { tatistica } \\
\text { ant); an }\end{array}$ & $\begin{array}{l}\text { ificant, } \\
1 \pm 0.06\end{array}$ & $\begin{array}{l}\text { 390); } \\
\text { (not }\end{array}$ & $\begin{array}{l}\text { Chromos } \\
0.105 \text { for } \\
0.103 \text { for } \\
\text { ant }\end{array}$ & $\begin{array}{r}2 /(2+4) \\
0.552 \pm 0 . \\
0.545 \pm 0\end{array}$ & $\begin{array}{l}\text { o confic } \\
\text { or }{ }^{\mathrm{e}} ; 0 . \\
\text { or }{ }^{\mathrm{h}} \text {. Nor }\end{array}$ & $\begin{array}{l}\text { limits were } \\
.178 \text { for } \text {; } \\
\text { statistically }\end{array}$ \\
\hline
\end{tabular}

chromosomes, respectively; $\mathrm{q}_{\mathrm{n}}$ and $\mathrm{q}_{\mathrm{exn}}$ are the probabilities of producing of LC+SA with the painted and other chromosomes, respectively.

The observed number of total rearrangements involving chromosome 2 was $125(58+67)$ and of chromosome $4103(47+56)$. Those values are in good agreement with the theoretical values of 127.4 $(63.7+63.7)$ and $100.6(50.3+50.3)$. The total observed number of translocations involving both chromosomes 2 and 4 was 123 and was slightly larger than 105 of dicentrics, although it is not statistically significant. When the original chromosome combination was $\mathrm{SC}+\mathrm{LA}$ and $\mathrm{LC}+\mathrm{SA}$, the number of dicentrics and translocations were 16 and 30, respectively. The yield of dicentrics was significantly lower than that of translocations in this case. Observed numbers of dicentrics involving chromosomes 2 and 4 were 7 and 9. Both of those values are much smaller than the theoretical values of 15.7 and 15.9. Observed numbers of translocations involving chromosomes 2 and 4 were 12 and 18. Those values are not significantly different in comparison to the theoretical values of 15.7 and 15.9. On the other hand, if the original chromosome combination was $\mathrm{LC}+\mathrm{SA}$ and $\mathrm{LC}+\mathrm{SA}$, the yields of dicentrics and translocations were 86 and 89. They are not significantly different from theoretical values. In combination 1 ( $\mathrm{SC}+\mathrm{LA}$ and SC + LA), the yields of dicentrics and translocations were 4 and 3 and do not contribute significantly to overall induction rates.

It seems that there is a special mechanism causing preferential reduction of dicentrics in reciprocal exchanges when original chromosomes were heteromorphic in the size of broken segments; one chromosome consists of a small centric piece and a large acentric fragment, and the other consists of a large centric piece and a small acentric fragment. Now that we could find such preferential reduction of dicentrics in reciprocal exchanges, we need to perform further studies, e.g., by painting other chromosomes to understand why such an interesting phenomenon is observed only in this combination.
Acknowledgements We thank Ms. Masako Minamihisamatsu, Ms. Shang Yi and Dr. Reiko Kanda (Radiation Hazards Research Group, NIRS) for technical assistance and advice, Dr. Yasuhiko Yoshimoto (Environmental Radiation Protection Research Group, NIRS) for advice about the statistical analysis, and reviewers for their valuable comments.

\section{References}

Bauchinger M, Schmid E, Zitzelsberger H, Braselmann H (1993) Radiation-induced chromosome aberrations analysed by twocolour fluorescence in situ hybridization with composite whole chromosome-specific DNA probes and a pancentromeric DNA probe. Int J Radiat Biol 64:179-184

Boei JJWA, Vermeulen S, Natarajan AT (1996) Detection of chromosomal aberrations by fluorescence in situ hybridization in the first three postirradiation divisions of human lymphocytes. Mutat Res 349:127-135

Cremer T, Popp S, Emmerich P, Lichter P, Cremer C (1990) Rapid metaphase and interphase detection of radiation-induced chromosome aberrations in human lymphocytes by chromosomal suppression in situ hybridization. Cytometry $11: 110-118$

Finnon P, Lloyd DC, Edwards AA (1995) Fluorescence in situ hybridization detection of chromosomal aberrations in human lymphocytes: applicability to biological dosimetry. Int J Radiat Biol 68:429-435

Hayata I, Tabuti H, Furukawa A, Okabe N, Yamamoto M, Sato K (1992) Robot system for preparing lymphocyte chromosome. J Radiat Res 33:Suppl. 231-241

Kanda R, Hayata I (1996) Comparison of the yields of translocations and dicentrics measured using conventional Giemsa staining and chromosome painting. Int $\mathbf{J}$ Radiat Biol 69:701-705

Knehr S, Huber R, Braselmann H, Schraube H, Bauchinger M (1999) Multicolor FISH painting for the analysis of chromosomal aberrations induced by $220 \mathrm{kV}$ X-rays and fission neutrons. Int J Radiat Biol 75:407-418

Lucas JN, Tenjin T, Straume T, Pinkel P, Moore II D, Litt M, Gray JW (1989) Rapid human chromosome aberration analysis using fluorescence in situ hybridization. Int $\mathbf{J}$ Radiat Biol $56: 35-44$

Luomahaara S, Lindholm C, Mustonen R, Salomaa S (1999) Distribution of radiation-induced exchanges in human chromosomes 1, 2 and 4. Int $\mathbf{J}$ Radiat Biol 75:1551-1556

Mayall BH, Carrano AV, Moore II DH, Ashworth LK, Benne DE and Mendelsohn ML (1984) The DNA-Based Human Karyotype. Cytometry 5:376-385 
Nakano M, Nakashima E, Pawel DJ, Kodama Y, Awa A (1993) Frequency of reciprocal translocations and dicentrics induced in human blood lymphocytes by X-irradiation as determined by fluorescence in situ hybridization. Int $\mathbf{J}$ Radiat Biol 64:565-569

Natarajan AT, Vyas RG, Darroudi F, Vermeulen A (1992) Frequencies of X-ray induced chromosome translocations in human peripheral lymphocytes as detected by in situ hybridization using chromosome specific DNA libraries. Int J Radiat Biol 61:199-203

Natarajan AT, Balajee AS, Boei JJWA, Chatterjee S, Darroudi F, Grigorova M, Noditi M, Oh HJ, Slijepcevic P, Vermeulen S (1994) Recent developments in the assessment of chromosomal damage. Int J Radiat Biol 66:615-623

Schmid E, Zitzelsberger H, Braselmann H, Gray JW, Bauchinger M (1992) Radiation-induced chromosome aberrations analysed by fluorescence in situ hybridization with a triple combination of composite whole chromosome-specific DNA probes. Int $\mathbf{J}$ Radiat Biol 62: 673-678
Tucker JD, Ramsey MJ, Lee DA, Minkler JL (1993) Validation of chromosome painting as a biodosimeter in human peripheral lymphocytes following acute exposure to ionizing radiation in vitro. Int J Radiat Biol 64:27-37

Tucker JD, Morgan WF, Awa AA, Bauchinger M, Blakey D, Cornforth MN, Littlefield LG, Jatarajan AT, Shasserre C (1995) A proposed system for scoring structural aberrations detected by chromosome painting. Cytogenet Cell Genet 68:211-221

Virsik-Peuckert P, Rave-Frank M, Langebrake U, Schmidberger H (1997) Differences in the yields of dicentrics and reciprocal translocations observed in the chromosomes of irradiated human skin fibroblasts and blood lymphocytes from the same healthy individuals. Radiat Res 148:209-215

Yamada K, Kasama M, Takai S (1996) Technical improvement and development for automated detection. In: Ministry of Health and Welfare (eds) Report on trial researches of nuclear power by national organizations, vol 35, pp 118-1-118-4 (in Japanese) 